University of Nebraska - Lincoln

DigitalCommons@University of Nebraska - Lincoln

1998

\title{
Interpreting Carnivore Scent-Station Surveys
}

\author{
Glen A. Sargeant \\ USGS Northern Prairie Science Center, gsargeant@usgs.gov \\ Douglas $\mathrm{H}$. Johnson \\ Northern Prairie Science Center, Douglas_H_Johnson@usgs.gov \\ William E. Berg \\ Minnesota Department of Natural Resources
}

Follow this and additional works at: https://digitalcommons.unl.edu/usgsnpwrc

Part of the Other International and Area Studies Commons

Sargeant, Glen A.; Johnson, Douglas H.; and Berg, William E., "Interpreting Carnivore Scent-Station Surveys" (1998). USGS Northern Prairie Wildlife Research Center. 223.

https://digitalcommons.unl.edu/usgsnpwrc/223

This Article is brought to you for free and open access by the US Geological Survey at DigitalCommons@University of Nebraska - Lincoln. It has been accepted for inclusion in USGS Northern Prairie Wildlife Research Center by an authorized administrator of DigitalCommons@University of Nebraska - Lincoln. 


\title{
INTERPRETING CARNIVORE SCENT-STATION SURVEYS
}

\author{
GLEN A. SARGEANT,' Northern Prairie Science Center, Biological Resources Division, U.S. Geological Survey, 8711 37th \\ Street SE, Jamestown, ND 58401, USA \\ DOUGLAS H. JOHNSON, Northern Prairie Science Center, Biological Resources Division, U.S. Geological Survey, 8711 37th \\ Street SE, Jamestown, ND 58401, USA \\ WILLIAM E. BERG, Minnesota Department of Natural Resources, 1201 East Highway 2, Grand Rapids, MN 55744, USA
}

\begin{abstract}
The scent-station survey method has been widely used to estimate trends in carnivore abundance. However, statistical properties of scent-station data are poorly understood, and the relation between scentstation indices and carnivore abundance has not been adequately evaluated. We assessed properties of scentstation indices by analyzing data collected in Minnesota during 1986-93. Visits to stations separated by $<2 \mathrm{~km}$ were correlated for all species because individual carnivores sometimes visited several stations in succession. Thus, visits to stations had an intractable statistical distribution. Dichotomizing results for lines of 10 stations ( 0 or $\geq 1$ visits) produced binomially distributed data that were robust to multiple visits by individuals. We abandoned 2-way comparisons among years in favor of tests for population trend, which are less susceptible to bias, and analyzed results separately for biogeographic sections of Minnesota because trends differed among sections. Before drawing inferences about carnivore population trends, we reevaluated published validation experiments. Results implicated low statistical power and confounding as possible explanations for equivocal or conflicting results of validation efforts. Long-term trends in visitation rates probably reflect real changes in populations, but poor spatial and temporal resolution, susceptibility to confounding, and low statistical power limit the usefulness of this survey method.
\end{abstract}

JOURNAL OF WILDLIFE MANAGEMENT 62(4):1235-1245

Key words: bias, carnivores, Minnesota, population index, population trend, precision, scent-station survey, validation.

Estimates of animal abundance are among the most important information needs of wildlife managers and researchers. Subjective estimates as simple as "common" or "scarce" sometimes suffice, but more objective measures are often needed. Unfortunately, secretive habits of most carnivore species and the low density of most carnivore populations preclude accurate, precise, and inexpensive estimation of population size. Hence, indices of relative abundance often substitute (see species accounts in Novak et al. 1987).

Tracks detected at scented baits (scent stations) have been used for decades to index abundances and monitor distributions of carni-

\footnotetext{
${ }^{1}$ E-mail: glen_sargeant@usgs.gov
}

vores (Cook 1949, Richards and Hine 1953, Wood 1959). To facilitate comparisons among such surveys, Linhart and Knowlton (1975) introduced a standardized protocol for collecting scent-station survey data. Modifications thereof quickly found widespread application by carnivore managers and researchers (Johnson and Pelton 1981), who regarded scent stations as an accurate and cost-effective means of monitoring trends in carnivore populations. However, despite the persistent belief that scent-station surveys provide useful information about carnivore population trends (Wood 1959, Linhart and Knowlton 1975, Roughton and Sweeny 1982, Linscombe et al. 1983, Leberg and Kennedy 1987, Travaini et al. 1996, and others), attempts to validate the method (Conner et al. 1983, 


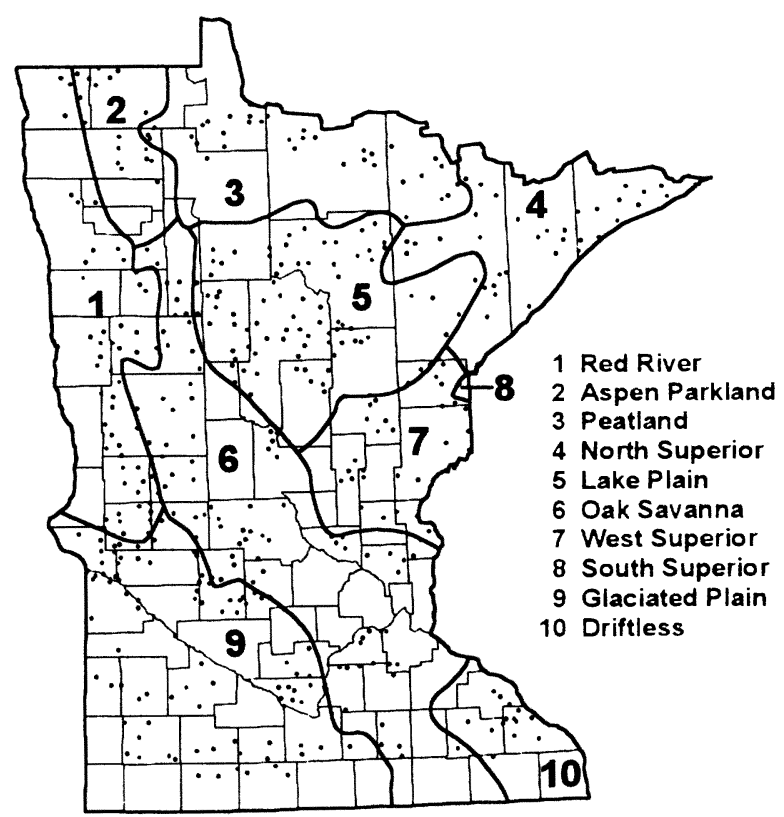

Fig. 1. Map of Minnesota showing biogeographic sections (sections) and locations of scent-station survey lines, $1986-93$. Boundaries of sections follow Bailey (1978), but section names are abridged.

Minser 1984, LeBerg and Kennedy 1987, Nottingham et al. 1989, Diefenbach et al. 1994, Smith et al. 1994, and others) have produced equivocal or conflicting results.

The Minnesota carnivore scent-station survey (B. Joselyn and S. Spoolman. 1981. Predator and furbearer scent post survey. Pages 295-315 in Project descriptions, unpublished. Minnesota Department of Natural Resources, St. Paul, Minnesota, USA.) is among the most intensive long-term applications of the scent-station method. We analyzed a subset of data from that survey to determine statistical properties and to examine analyses of scent-station data. To determine sources of disagreement among validation studies and to evaluate the usefulness of survey results, we also reevaluated recent validation studies of Smith et al. (1994) and Diefenbach et al. (1994). Objectives of this paper are (1) identify key features of scent-station data; (2) discuss implications of those features for the design, analysis, and interpretation of scent-station surveys; (3) discuss a simple method of analyzing trends in scent-station indices; and (4) reevaluate the relation between scentstation visitation rates and carnivore abundance.

\section{METHODS}

\section{Minnesota Scent-Station Survey}

We obtained field data collected annually in Minnesota during 1986-93. A scent station con- sisted of a 0.9-m-diameter circle of smoothed earth with a fatty-acid scent tablet placed at the center (Linhart and Knowlton 1975). Scent stations were placed along unpaved roads at intervals of $480 \mathrm{~m} ; 10$ stations constituted a line. Placement of lines was nonrandom, but 441 lines were distributed throughout the state (Fig. 1). Minimum spacing between lines was $5 \mathrm{~km}$. Most lines were operated for 1 night each year between late August and mid-October, although some could not be operated every year. Presence or absence of tracks was recorded for individual species when stations were checked the day after activation. Methods were generally consistent with those described by Linhart and Knowlton (1975) as modified by Roughton and Sweeny (1982).

We report results for gray wolves (Canis lupus), coyotes (C. latrans), red foxes (Vulpes vulpes), skunks (mostly Mephitis mephitis, but also Spilogale putorius), raccoons (Procyon lotor), and bobcats (Felis rufus). These species have been monitored elsewhere with scent stations and embody diverse physical and behavioral adaptations that may affect the usefulness of scent-station surveys. Where possible, we present $P$-values to enable readers to judge statistical significance for themselves; where unavoidable, we infer significance from $P \leq 0.05$. Many biologists, however, consider the conse- 
quences of Type II errors more serious than those of Type I errors when testing for population trend and are thus willing to accept Type I error rates much greater than $P=0.05$ (up to $P=0.20$ for scent-station data; Zielinski and Stauffer 1996).

We analyzed 2 indices: (1) the proportion of stations (station index), and (2) the proportion of lines (line index) within a biogeographic section (section; Fig. 1) at which a species was detected. For some goodness-of-fit tests, data were grouped by county within section (when section boundaries subdivided counties, each portion was treated separately). When calculating annual means for the entire state, we corrected for nonrandom sampling by weighting results for each section in proportion to its area. Because of the limited geographic extent and small sample size of the South Superior section, results were combined with those of the West Superior section. Visitation rates were estimated 2 ways: (1) from the entire dataset, and (2) with the geographic extent of surveys restricted to sections where species were detected at least once.

For each species, we used linear regression to compare the rank order of index values with the temporal ordering of surveys and thereby determine whether index values exhibited sustained increasing or decreasing trends. We included section, year, and their interaction in regression models and tested statewide trends when interactions were nonsignificant. We tested trends separately for each section when interactions were detected. We also plotted indices against time to check for evidence of nonmonotonic trends with management significance.

The binomial distribution is sometimes regarded as a statistical model for the number of scent stations visited (Sumner and Hill 1980, Diefenbach et al. 1994, Smith et al. 1994). For each species and county, we computed expected numbers of lines receiving $i=[0, \ldots, 10]$ visits from a binomial distribution and the average visitation rate. Summing across counties gave expected values of a multinomial distribution with 11 cells, with the frequency in cell $i$ corresponding to the numbers of lines receiving $i$ $=[0, \ldots, 10]$ visits. We used chi-square goodness-of-fit tests to compare field data to expected values. Significant differences implied local spatial heterogeneity of visitation rates or spatial correlations among visits, and hence inadequacy of the binomial distribution as a model for visitation for the species in question. This method was also used to compare observed numbers of lines visited per county with expected values computed from section-specific visitation rates. We present results obtained after combining number-of-visits categories until expected values exceeded 5, which assured chi-square distributions for test statistics (Sprent 1989), but combining categories did not affect conclusions. To safeguard against Type II errors, we used Fisher's inverse chi-square test (Hedges and Olkin 1985) to determine whether $P$-values were uniformly distributed when the null hypothesis could not be rejected for any species.

We used indicator variograms (Rossi et al. 1992) to examine spatial correlations among visits to scent stations. We excluded data collected during 1992-93 from this analysis because they were provided in a format that did not distinguish the position of stations within lines. We also excluded lines receiving $<2$ visits in a year because they did not provide information about spatial relations among multiple visits. We used remaining data to plot average squared differences between results ( $1=$ visit, $0=$ no visit) for stations within lines and years against 480$\mathrm{m}$ separation intervals ranging from 480 to $4,320 \mathrm{~m}$. Because average squared differences are larger when data are independent than when they are positively spatially correlated, trends in variograms provided visual evidence if correlations were related to the distance between stations (Rossi et al. 1992).

\section{Reevaluations of Validation Experiments}

We reevaluated 2 recent experiments to investigate reasons for equivocal results of validation studies. In the first, Smith et al. (1994) manipulated the abundance of raccoons on Davies Island, Tennessee, during 1988-89 while monitoring visits to scent stations. They used Spearman's rank correlation to test for a relation between estimates of minimum abundance and visitation rate, and logistic analysis to test for differences in visitation between low ( $\leq 35$ individuals) and high ( $>35$ ) estimated population levels and between seasons. Neither a correlation nor an effect of population level was detected by Smith et al. (1994).

We simulated data similar to those Smith et al. (1994) would have obtained if their population estimates were correct, distributional assumptions of their logistic analyses were met, 
and raccoons visited scent stations at a rate linearly related to population size. Although Smith et al. (1994) included data from 20 surveys in their analyses, we simulated only 14 surveys. We omitted 6 consecutive surveys conducted during winter, when raccoons never visited scent stations. We set $S_{j}$ to correspond to the number of stations and $N_{j}$ to correspond to the estimated population size for survey $j$. The binomial probability, $P_{N_{j}}$, was linearly related to $N_{j}$ by the equation

$$
P_{N_{j}}=\hat{A} N_{j}
$$

where

$$
\hat{A}=\frac{1}{14} \sum_{i=1}^{14}\left[x_{i} /\left(S_{i} \hat{N}_{i}\right)\right],
$$

and where $x_{i}$ was the number of visits, $S_{i}$ was the number of stations, and $\hat{N}_{i}$ was the estimated size of the raccoon population for the $i$ th survey. Thus, $\hat{A}$ was the average number of visits observed per raccoon per station. Finally, we used $S_{j}, P_{N_{j}}$ to generate datasets of 14 binomial $\left[\operatorname{BIN}\left(S_{j}, P_{N_{j}}\right)\right]$ random variables, $\left\{x_{j}\right\}_{j=1}^{14}$. Simulated data did not vary seasonally, so we did not incorporate seasonal effects in our model, but otherwise used the same methods of analysis as Smith et al. (1994). Distributions of Spearman's rank correlations and of $P$-values for logistic analyses were estimated by analyzing 10,000 simulated datasets generated by the RANBIN function of SAS (SAS Institute 1988).

The second experiment we reevaluated was conducted by Diefenbach et al. (1994), who introduced bobcats onto Cumberland Island, Georgia, during September of 1988. Diefenbach et al. (1994) conducted 14 scent-station surveys as the population expanded from periodic introductions of additional bobcats and, after the first year, from reproduction as well. They used linear regression to relate inverse visitation rates ( $1 /$ rate) to estimates of bobcat abundance after deleting 1 survey considered an outlier. We used the same data and multiple regression to determine whether the relation between inverse visitation rates and estimated abundance (Diefenbach et al. 1994) could be explained as plausibly by confounding factors that differed between 2 time periods (before 28 Feb and after 11 Sep, 1989). During the first time period, the bobcat population included only recently introduced individuals. During the second time period, the bobcat population included adults from the original introduction and their progeny, in addition to recently introduced animals. We compared models with respect to explained variation and adherence to assumptions of multiple regression.

\section{RESULTS}

\section{Minnesota Scent-Station Survey}

Neither wolves nor bobcats were reported in the Driftless or Glaciated Plain sections. Bobcats were not reported in the Red River section. Other species were reported in all sections. Deleting sections where species were not reported did not affect conclusions drawn from analyses. Results are therefore based on visitation rates estimated from the entire dataset. We obtained qualitatively similar results for station and line indices (Fig. 2). However, conclusions of statistical tests performed at conventional significance levels $(P=0.05)$ would have differed.

Our regression analysis resulted in estimates of trend (increasing or decreasing) and associated $P$-values that readers should use to judge statistical significance for themselves. Weighted statewide station indices increased from 1986 to 1993 for wolves $\left(F_{1,6}=37.56, P<0.001\right)$, coyotes $\left(F_{1,6}=13.64, P=0.01\right)$, red foxes $\left(F_{1,6}=\right.$ 11.41, $P=0.01)$, raccoons $\left(F_{1,6}=37.56, P<\right.$ $0.001)$, and bobcats $\left(F_{1,6}=4.23, P=0.09\right)$, but declined for skunks $\left(F_{1,6}=2.27, P=0.18\right)$. However, these statewide analyses obscured differences in section trends for coyotes $\left(F_{8,54}=\right.$ 2.18, $P=0.04)$ and raccoons $\left(F_{8,54}=2.35, P=\right.$ $0.03)$, but not other species $(P \geq 0.13)$ that would have been significant at conventional probability levels $(P=0.05)$. Station indices for coyotes declined in the West Superior and Peatland sections but increased elsewhere (Table 1). For raccoons, station indices increased in all but the Peatland section, where they declined (Table 1).

Weighted statewide line indices increased for wolves $\left(F_{1,6}=20.79, P<0.01\right)$, coyotes $\left(F_{1,6}=\right.$ 4.23, $P=0.09)$, red foxes $\left(F_{1,6}=37.56, P<\right.$ $0.001)$, raccoons $\left(F_{1,6}=16.62, P<0.01\right)$, and bobcats $\left(F_{1,6}=4.80, P=0.07\right)$, but declined for skunks $\left(F_{1,6}=3.29, P=0.12\right)$. Statewide analyses obscured statistically significant differences in section trends for skunks $\left(F_{8,54}=2.24\right.$, $P=0.04)$ and raccoons $\left(F_{8,54}=2.07, P=0.05\right)$ but not other species $(P \geq 0.23)$. Line indices for skunks increased in the West Superior, North Superior, and Driftless sections, but declined elsewhere (Table 1). Raccoon indices de- 

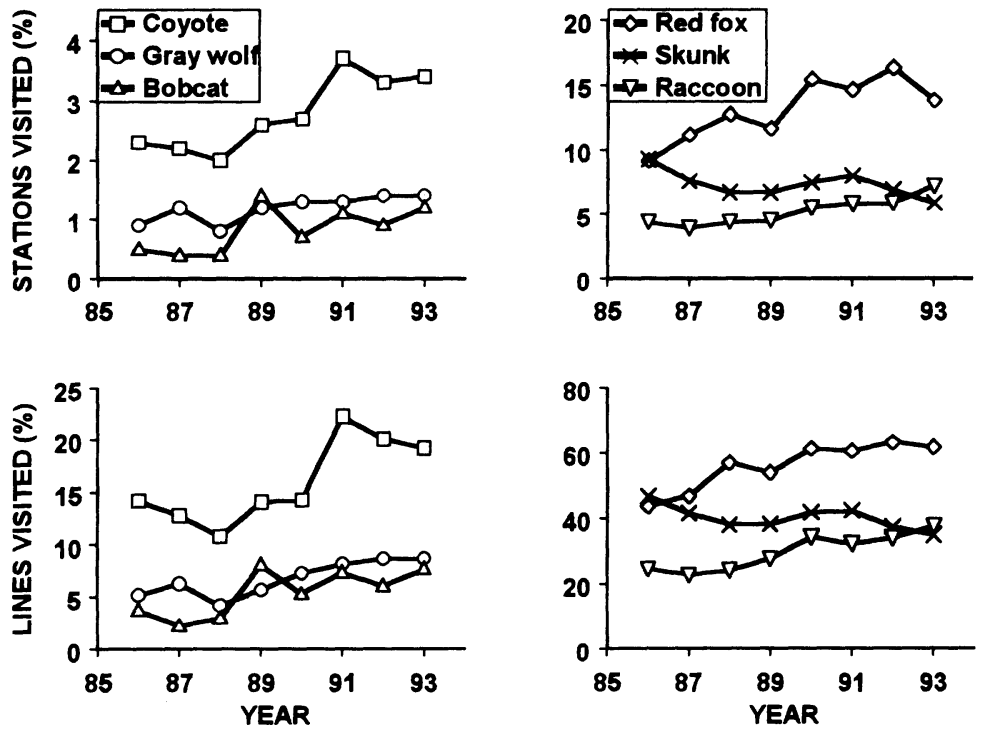

Fig. 2. Statewide trends in carnivore scent-station indices for Minnesota, 1986-93. Results are shown for stations and for lines of 10 stations placed at $480-\mathrm{m}$ intervals. Annual means are weighted averages of means for sections, with weights proportional to the geographic area of sections.

clined in the Peatland section but increased elsewhere (Table 1). Tests could have failed to detect important nonmonotonic trends, so we checked statistical results by plotting index values against time. Undetected trends were not evident in the Minnesota data.

For all species except raccoons, line indices were lower and multiple visits per line more frequent than expected $(P<0.001)$ if visits to stations occurred independently at a constant rate (Table 2). Thus, for most species, the binomial distribution was not an appropriate model for visits to stations. For most species, average squared differences between results for stations increased with the distance between stations until stations were separated by $2.0-2.5$ $\mathrm{km}$, but they seemed to decrease again at distances $>3,000 \mathrm{~m}$ (Fig. 3). Similar results for closely spaced stations are indicative of multiple visits by individual carnivores or a tendency for closely spaced stations to be placed in similar habitats. Stations near the opposite ends of lines, however, also produced surprisingly similar results. We could not determine the cause of this phenomenon. Locations of stations within lines did not seem to affect visitation rates; other possible explanations include observer bias and systematic, short-scale variation in use of the landscape by carnivores.

Whether or not a line received 0 or $\geq 1$ visit did not appear to depend on results for other lines in the same section: goodness-of-fit tests failed to reject the hypothesis of independence for any species $(P \geq 0.17$; Table 2$)$. Fisher's inverse chi-square test failed to reveal any deviation of $P$-values from uniformity $\left(\chi_{12}^{2}=8.18\right.$, $P=0.84$ ), providing further evidence the binomial distribution was a reasonable model for numbers of lines visited within sections.

\section{Reevaluations of Validation Experiments}

Our analysis of simulated data indicated tests performed by Smith et al. (1994) had extremely low power for detecting differences in visitation rates that may have resulted from changes in raccoon abundance on Davies Island. Spearman's rank correlation analysis of simulated data patterned after Smith et al. (1994) detected a direct relation between abundance and visitation for a 1-tailed test at $P \leq 0.05$ in only $18.3 \%$ of 10,000 trials (Fig. 4). Logistic analysis detected a density-related difference in overall visitation at $P \leq 0.05$ in only $12.6 \%$ of 10,000 trials (Fig. 5).

Abundance explained $73 \%$ of variation in inverse visitation rates of bobcats on Cumberland Island $\left(F_{1,12}=32.52, P<0.001\right)$. However, within time periods, visitation rates did not increase with population size (Fig. 6). A model that adjusted for differences between time periods explained $79 \%$ of variation in inverse visitation rates $\left(F_{1,12}=45.69, P<0.001\right)$, left no 


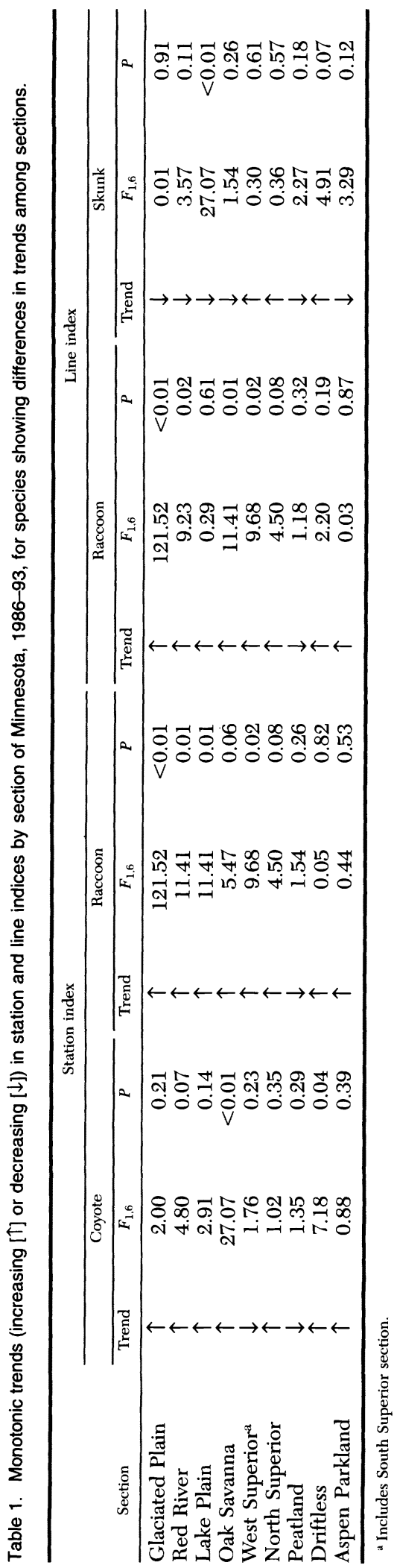

Table 2. Results of chi-square goodness-of-fit tests for independence of visits by carnivores to scent stations within scentstation lines, and for independence of visits to scent-station lines within sections of Minnesota, 1986-93.

\begin{tabular}{|c|c|c|c|c|c|c|}
\hline & \multicolumn{3}{|c|}{$\begin{array}{l}\mathrm{H}_{0}: \text { Visits to stations } \\
\text { are independent } \\
\text { within lines }\end{array}$} & \multicolumn{3}{|c|}{$\begin{array}{l}\mathrm{H}_{0}: \text { Visits to lines } \\
\text { are independent } \\
\text { within sections }\end{array}$} \\
\hline & $\mathrm{df}$ & $x^{2}$ & $P$ & $\mathrm{df}$ & $x^{2}$ & $P$ \\
\hline Gray wolf & 3 & 96.55 & $<0.001$ & 4 & 0.35 & 0.99 \\
\hline Coyote & 4 & 44.58 & $<0.001$ & 5 & 2.17 & 0.82 \\
\hline Red fox & 7 & 174.39 & $<0.001$ & 9 & 5.54 & 0.78 \\
\hline Skunk & 6 & 43.04 & $<0.001$ & 8 & 8.62 & 0.38 \\
\hline Raccoon & 5 & 8.56 & 0.13 & 6 & 6.12 & 0.41 \\
\hline Bobcat & 2 & 14.83 & $<0.001$ & 3 & 5.02 & 0.17 \\
\hline
\end{tabular}

statistical evidence for an additional effect of abundance $\left(F_{1,11}=0.39, P=0.55\right)$, and produced normally distributed, homoscedastic, independent residuals. Moreover, we found nearly significant differences between time periods that could not be explained by changes in abundance $\left(F_{1,11}=3.98, P=0.07\right)$. Assigning data to 1 of 2 time periods was superior to regressing them on abundance with respect to both explanatory value and adherence to model assumptions. Both models were biologically plausible.

\section{DISCUSSION}

\section{Features of Scent-Station Data}

Stations, lines, and surveys are the 3 experimental units used most frequently in analyses of scent-station data. The use of stations is motivated by the availability of convenient methods for analyzing binary data, a desire to retain the appearance of a large sample size, or a shortage of experimental units when stations are grouped. Suspected correlations between closely spaced stations motivate the use of lines (e.g., Roughton and Sweeny 1982). In a few instances (e.g., Diefenbach et al. 1994, this study), the issue of independence has been avoided by treating the overall visitation rate for each survey occasion as a datum.

Effective tests for spatial dependence require large datasets, especially when visitation rates are low. We have not encountered such tests in the scent-station literature. Our analysis of data collected in Minnesota revealed spatial correlations between stations that extended to approximately $2,000 \mathrm{~m}$. Effects of station spacing were especially strong for mobile habitat generalists that defend territories to varying degrees (wolves, coyotes, red foxes, bobcats), and 

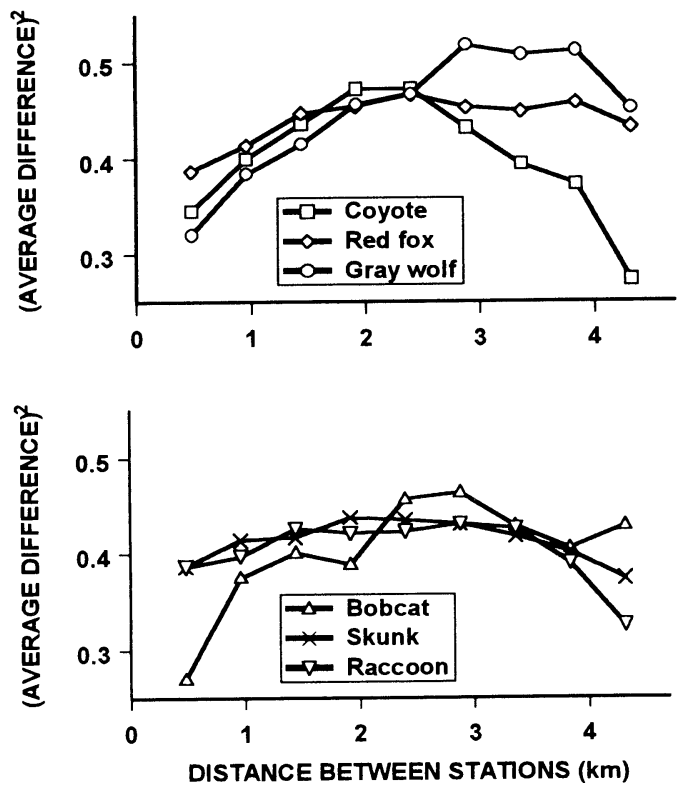

Fig. 3. Indicator variograms for detections at scent stations within lines in Minnesota, 1986-91. Variograms are restricted to lines with $\geq 2$ stations visited within the same year.

were much weaker for less-mobile species that display stronger habitat preferences (skunks, raccoons). Thus, multiple visits by individuals are the probable cause of spatial correlations.

In Minnesota, spatial correlations had 2 practical consequences. First, statistical tests detected differences more often than they should have when we treated stations as independent experimental units. Second, a few lines with many visits had disproportionate influence on

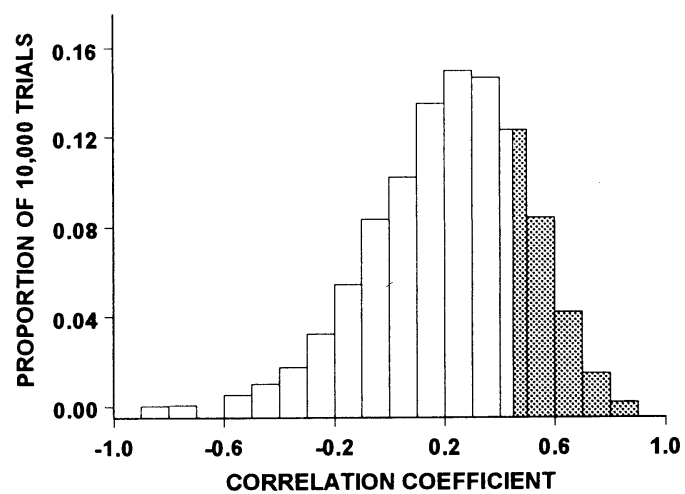

Fig. 4. Distribution of Spearman's rank correlations between population size and visitation rate for 10,000 sets of simulated binomial data directly relating animal abundance to visitation rate. Data were modeled after scent-station surveys of raccoons conducted by Smith et al. (1994). Correlations within the shaded region are significant at $P \leq 0.05$ (1-tailed test).

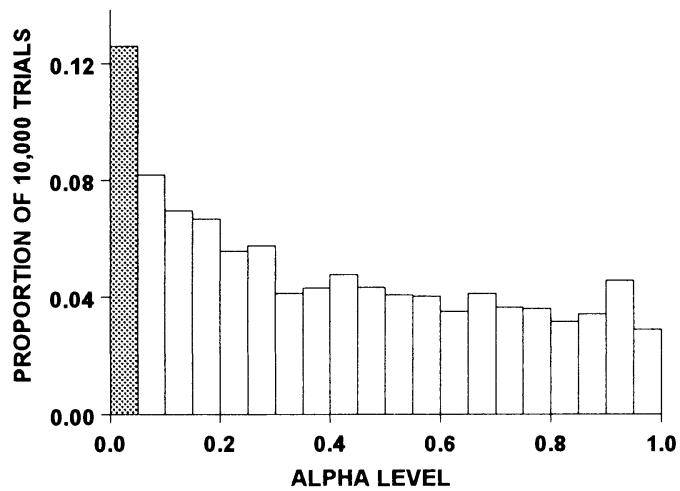

Fig. 5. Distribution of $P$-values obtained for 10,000 logistic analyses of simulated binomial data directly relating abundance to visitation rate. Data were modeled after scent-station surveys of raccoons conducted by Smith et al. (1994). P-values $<0.05$ are shaded.

conclusions for some species, years, and sections. We countered the disproportionate influence of these lines by dichotomizing the result for each line (no visit, $\geq 1$ visit). The resulting line index was robust to effects of nonrandom line placement, behavioral differences among carnivores, and observer error. Whereas the number of stations visited had an intractable statistical distribution, the number of lines visited was a binomial variable. These benefits outweighed the only disadvantage: a possible reduction of statistical power. Other means of reducing the weight afforded to multiple visits (e.g., the square-root transformation) produced intractable data-expressed in inconvenient units of measure.

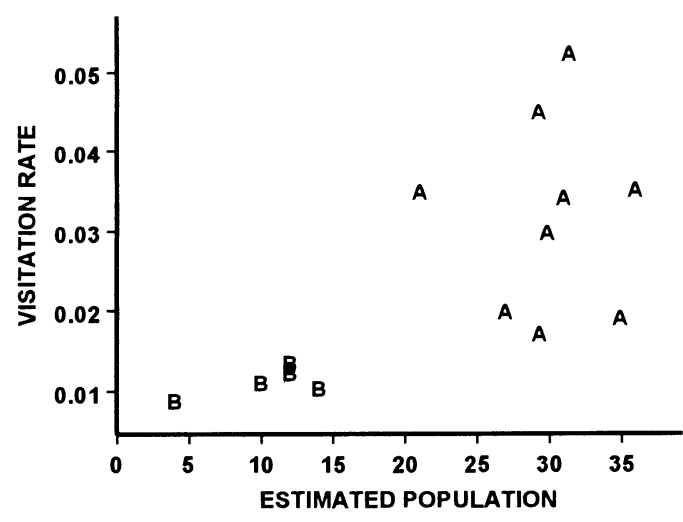

Fig. 6. Visitation rates for bobcats to scent stations on Cumberland Island, Georgia, after (A) 11 September 1989, and before (B) 28 February 1989, and (Diefenbach et al. 1994). 


\section{Statistical Comparisons of Scent-Station Data}

Most analyses of scent-station surveys include a statistical comparison of visitation rates across time periods: the null hypothesis is that rates are identical for 2 or more periods. The value of such tests is unclear because visitation rates are unlikely to be identical for any 2 periods, and observed differences may be due to factors other than abundance (Sumner and Hill 1980, Griffith et al. 1981, Morrison et al. 1981, Nottingham et al. 1989). Moreover, methods used for comparisons of time periods (e.g., randomization tests [Roughton and Sweeney 1982]; categorical models [Sumner and Hill 1980]; parametric and nonparametric analysis of variance [Conner et al. 1983, Travaini et al. 1996]; and logistic regression [Smith et al. 1994]) declare arbitrarily small differences to be statistically significant when sample sizes are adequately large. For many types of data, such difficulties can be overcome by declaring a minimum effect size that will be considered biologically important, not merely statistically significant. Relations between scent-station indices and carnivore abundance, however, are unknown and nonlinear (Linhart and Knowlton 1975); hence, specifying an effect size is problematic.

Instead of comparing time periods, we used regression of rank-transformed data to test for trends. The method provided an approximate test for homogeneity of trends among sections and a general test for sustained trend of any form (e.g., linear, quadratic, logarithmic). When the null hypothesis was rejected for a section, the observed ordering of survey results was unlikely to have occurred in the absence of an increasing or decreasing trend in visitation. Whereas differences in visitation between time periods can result from changes in factors other than abundance, such factors fluctuate irregularly from year-to-year and are comparatively unlikely to cause significant trends in visitation. To be detectable, trends must be large in comparison with annual fluctuations, and hence of significance to wildlife managers. In short, regression of rank-transformed data is simple to apply, robust to spurious conclusions, easy to interpret, and readily detected trends in our data. The principal challenge was choosing a time span for testing. Monotonic trends across years do not persist indefinitely, but analyses of very short spans are susceptible to confounding and have low statistical power.

Linhart and Knowlton (1975) and Roughton and Sweeny (1982) cautioned against using scent stations to compare carnivore abundance among areas of dissimilar habitat because differences in sampling biases and differences in carnivore abundance may both affect survey results. Unlike temporal biases, confounding effects of habitat differences persist through time. Unless they can be accounted for, spatial comparisons can easily lead to spurious conclusions. Thus, we did not attempt spatial comparisons of visitation rates. However, we did test the consistency of trends across sections and detected differences that document problems with pooling data from different habitats or geographic regions. In Minnesota, strong trends in a few areas contributed disproportionately to statewide trends in line indices for skunks and raccoons. Important local trends may, in some cases, cancel one another. Analyses of statewide trends for all species would have sacrificed resolution that is useful to managers.

\section{Validation Experiments}

Numerous attempts have been made to validate scent-station surveys by correlating visitation with estimates of carnivore abundance or with other indices (Conner et al. 1983, Leberg and Kennedy 1987, Diefenbach et al. 1994, Smith et al. 1994). A potentially useful relation has been reported by some authors (Conner et al. 1983, Linscombe et al. 1983, Leberg and Kennedy 1987, Diefenbach et al. 1994), but not by others (Nottingham et al. 1989, Smith et al. 1994), and the validity of some reported relations has been challenged (Minser 1984, Nottingham et al. 1989). Equivocal results of validation studies made us reluctant to draw inferences about carnivore abundance in Minnesota without first investigating sources of disagreement. Hence, we reevaluated data from 2 recent and comparatively rigorous experimental tests of scent-station methodology.

Our reevaluation of Smith et al. (1994) emphasized the role sample size plays in the outcome of validation experiments. The stated purpose of that study was to test the null hypothesis that visitation rates of raccoons were not independent of population density. The null hypothesis actually tested, however, was the opposite. After failing to detect a relation between visitation and abundance, the authors concluded 
that changes in density may precipitate changes in behavior that preclude the use of scent stations to index raccoon abundance. Our simulations implicate low statistical power as a more parsimonious and equally convincing explanation for results obtained by Smith et al. (1994), even though we probably overestimated the power of their tests (simulated data were not affected by errors in estimates of population size, seasonal variation in visitation rates, or observer error). Thus, it is appropriate to conclude the survey was not a useful index to raccoon abundance on Davies Island because it was deficient in statistical power. A more complicated biological explanation is unnecessary, and results of Smith et al. (1994) should not be generalized to other situations.

Our reevaluation of Diefenbach et al. (1994) highlights the importance of including experimental controls when designing validation experiments. Factors that influence carnivore movements affect the rate at which carnivores encounter stations. The motivation for carnivores to investigate attractants may include such factors as curiosity, hunger, or sexual interest, and these factors must compete with wariness toward attractants. Thus, weather (Leberg et al. 1983, Nottingham et al. 1989), season (Griffith et al. 1981, Smith et al. 1994), habitat characteristics (Linhart and Knowlton 1975, LeCount 1982, Nottingham et al. 1989), and human activity (Griffith et al. 1981, Andelt et al. 1985) are thought to affect visitation rates. The experimental design of Diefenbach et al. (1994) did not permit effects of likely confounders to be distinguished from effects of abundance. Effects of confounders were unambiguously suggested by our results, but effects of abundance were not.

The general validity of scent-station indices has been neither proven nor called into serious question by objective validation experiments. Moreover, we believe logistical constraints will preclude conclusive, experimental validation in many settings and for many species. Powerful experiments require estimation and manipulation of carnivore populations over a larger area than was feasible for Smith et al. (1994; W. P. Smith, U.S. Forest Service, personal communication). Similar practical considerations precluded experimental control at Cumberland Island (D. R. Diefenbach, Pennsylvania Game Commission, personal communication). Yet, we chose these 2 examples for review because they are among the largest, most sophisticated validation studies that have been conducted.

\section{MANAGEMENT IMPLICATIONS}

Despite equivocal results of validation experiments, widespread correlative evidence suggests scent-station surveys are useful if limitations are respected. In Louisiana (Linscombe et al. 1983) and Minnesota (this study), scent-station indices were consistent with subjective assessments of regional abundance of individual species and reflected the geographic expansion of coyote populations. In Tennessee, monthly scent-station visitation rates were significantly correlated with estimates of raccoon population density (Leberg and Kennedy 1987). In Alabama, scent-station surveys and predator calling gave similar results for bobcats (Sumner and Hill 1980). Best and Whiting (1990) observed a reduction in visitation by opossums (Didelphis virginiana) and raccoons after populations of both species had been reduced by trapping. Thus, we believe long-term trends in visitation rates reflect real changes in populations.

However, available evidence supports use of scent stations only for monitoring broad temporal trends in relative abundance at an intermediate scale of spatial resolution (e.g., by section). The method is ill-suited for monitoring species that are rarely detected, and for localized monitoring of wide-ranging carnivores. Many studies have used only a few dozen stations per survey, but reliable results may require hundreds of lines of many stations (Zielinski and Stauffer 1996), especially for species detected infrequently. Hence, the perception that scent-station surveys are cost-effective may not reflect the cost of obtaining a useful number of samples.

To obtain reliable results, investigators must use analyses that accommodate statistical properties of scent-station data. Individual carnivores respond differently to stations and are not equally detectable. Repeated sampling of the same individual is pseudoreplication and affords undue influence to individuals that visit many stations in succession. Lines are an appropriate experimental unit. Dichotomizing results for lines produces data with a tractable statistical distribution and affords equitable influence to individual carnivores.

Finally, scent-station indices cannot yet be converted to estimates of abundance. Thus, it is difficult to determine from survey results when 
management responses are warranted. Scent stations can be used to help identify trends, but they should supplement, rather than replace, information from other sources. In this supplementary capacity, scent-station surveys are likely to remain a useful tool for carnivore research and management.

\section{ACKNOWLEDGMENTS}

We thank the Minnesota Department of Natural Resources (MDNR) and D. R. Diefenbach, Pennsylvania Game Commission, for providing survey data. In Minnesota, survey cooperators included the MDNR Wildlife Division; MDNR St. Croix State Park; U.S. Fish and Wildlife Service National Wildlife Refuges and Wetland Management Districts; the Cass and Beltrami County Land Departments; the Fond du Lac, White Earth, and Leech Lake Indian Reservations; the 1854 Treaty Authority; the University of Minnesota Itasca Biological Station; and Chippewa and Superior national forests. Survey efforts were coordinated by W. E. Berg. W. Snow assisted with data entry. H. T. Sklebar assisted with Geographic Information System hardware and software. T. L. Shaffer, E. V. Nordheim, and W. E. Newton offered statistical advice. Review comments of R. J. Greenwood, A. B. Sargeant, M. A. Sovada, B. S. Yandell, and an anonymous reviewer improved early drafts of this manuscript; we are especially grateful to D. R. Diefenbach and W. P. Smith for reviewing and improving our treatment of their work. We thank R. A. Garrott and R. L. Ruff for administrative support and helpful discussion. Funding for analyses and manuscript preparation was provided by the Northern Prairie Wildlife Research Center and the Wisconsin Cooperative Wildlife Research Unit of the Biological Resources Division, U.S. Geological Survey, and by the Graduate School, Department of Wildlife Ecology, and College of Agriculture and Life Sciences at the University of WisconsinMadison.

\section{LITERATURE CITED}

ANDElT, W. F., C. E. HaRris, and F. F. KNOWLton. 1985. Prior trap experience might bias coyote responses to scent stations. Southwestern Naturalist 30:317-318.

BAILEY, R. G. 1978. Description of the ecoregions of the United States. U.S. Forest Service, Intermountain Region, Ogden, Utah, USA.

BEST, M. S., AND R. M. Whiting, JR. 1990. Trappinginduced changes in scent-station visits by opos- sums and raccoons. Pages 94-99 in P. R. Krausman and N. S. Smith, editors. Managing wildlife in the Southwest. Arizona Chapter, The Wildlife Society, Tucson, Arizona, USA.

Conner, M. C., R. F. LABISKy, and D. R. ProgulSKE, JR. 1983. Scent-station indices as measures of population abundance for bobcats, raccoons, gray foxes, and opossums. Wildlife Society Bulletin 11:146-152.

Cook, A. H. 1949. Fur-bearer investigation. New York State Conservation Department, Federal Aid in Wildlife Restoration Project 10R, Supplement G, Final Report.

Diefenbach, D. R., M. J. CONROY, R. J. WARREN, W. E. James, L. A. BAKER, AND T. HON. 1994. A test of the scent-station survey technique for bobcats. Journal of Wildlife Management 58:10 17.

Griffith, B., H. M. Wight, W. S. Overton, AND E. C. MESLOW. 1981. Seasonal properties of the coyote scent station index. Pages 197-220 in F. L. Miller, A. Gunn, and S. R. Hieb, editors. Symposium on census and inventory methods for populations and habitats. Forest, Wildlife and Range Experiment Station, University of Idaho, Moscow, Idaho, USA.

HedGES, L. V., AND I. OLKIN. 1985. Statistical methods for meta-analysis. Academic Press, Boston, Massachusetts, USA.

Johnson, K. G., AND M. R. Pelton. 1981. A survey of procedures to determine relative abundance of furbearers in the southeastern United States. Proceedings of the Annual Conference of the Southeastern Association of Fish and Wildlife Agencies 35:261-272.

Leberg, P. L., AND M. L. Kennedy. 1987. Use of scent-station methodology to assess raccoon abundance. Proceedings of the Annual Conference of the Southeastern Association of Fish and Wildlife Agencies 41:394-403.

- - - AND R. A. VAN DEN Bussche. 1983. Opossum demography and scent-station visitation in western Tennessee. Proceedings of the Annual Conference of the Southeastern Association of Fish and Wildlife Agencies 37:34-40.

LECounT, A. L. 1982. Scent-station locations effect on estimating black bear abundance. Annual Conference of the Western Association of Fish and Wildlife Agencies 41:394-403.

LINHART, S. B., AND F. F. KNOWLTON. 1975. Determining the relative abundance of coyotes by scent station lines. Wildlife Society Bulletin 3:119-124.

Linscombe, G., N. Kinler, AND V. WRIGHT. 1983. An analysis of scent station response in Louisiana. Proceedings of the Annual Conference of the Southeastern Association of Fish and Wildlife Agencies 37:190-200

MiNSER, W. G., III. 1984. Comments on scent-station method for monitoring furbearers. Wildlife Society Bulletin 12:328.

Morrison, D. W., R. M. Edmunds, G. LinsCOMBE, AND J. W. GoErTZ. 1981. Evaluation of specific scent station variables in northcentral Louisiana. Proceedings of the Annual Conference of the Southeastern Association of Fish and Wildlife Agencies 35:281-291. 
Nottingham, B. G., JR., K. G. Johnson, and M. R. PELTON. 1989. Evaluation of scent-station surveys to monitor raccoon density. Wildlife Society Bulletin 17:29-35.

NovaK, M., J. A. BaKer, M. E. Obbard, AND B. MALLOCH, editors. 1987. Wild furbearer management and conservation in North America. Ontario Trapper's Association, North Bay, Ontario, Canada.

RICHARDS, S. H., AND R. L. HINE. 1953. Wisconsin fox populations. Wisconsin Conservation Department Technical Wildlife Bulletin 6 .

Rossi, R. E., D. J. Mullah, A. G. Journel, and E. H. Franz. 1992. Geostatistical tools for modeling and interpreting ecological spatial dependence. Ecological Monographs 62:277-314.

Roughton, R. D., AND M. D. SWEeny. 1982. Refinements in scent-station methodology for assessing trends in carnivore populations. Journal of Wildlife Management 46:217-229.

SAS INSTITUTE. 1988. SAS language guide for personal computers. Release 6.03 edition. SAS Institute, Cary, North Carolina, USA.

SMITH, W. P., D. L. BordEN, AND K. M. ENDRES. 1994. Scent-station visits as an index to abun- dance of raccoons: an experimental manipulation. Journal of Mammalogy 75:637-647.

SPRENT, P. 1989. Applied nonparametric statistical methods. Chapman \& Hall, London, United Kingdom.

Sumner, P. W., AND E. P. HILL. 1980. Scent-stations as indices of abundance in some furbearers of Alabama. Proceedings of the Annual Conference of the Southeastern Association of Fish and Wildlife Agencies 34:572-583.

Travaini, A., R. Laffitte, and M. Delibes. 1996. Determining the relative abundance of European red foxes by scent-station methodology. Wildlife Society Bulletin 24:500-504.

WoOD, J. E. 1959. Relative estimates of fox population levels. Journal of Wildlife Management 23: 53-63.

ZiElinski, W. J., AND H. B. Stauffer. 1996. Monitoring Martes populations in California: survey design and power analysis. Ecological Applications 6:1254-1267.

Received 6 January 1997.

Accepted 10 February 1998.

Associate Editor: Hobbs. 